\title{
The Impact of Chronic Kidney Disease on Peripheral Artery Disease and Peripheral Revascularization
}

\author{
Raffaele Serra (D) ${ }^{1,2, *}$ \\ Umberto Marcello Bracale ${ }^{3, *}$ \\ Nicola lelapi ${ }^{4}$ \\ Luca Del Guercio ${ }^{3}$ \\ Maria Donata Di Taranto (iD ${ }^{5}$ \\ Maurizio Sodo ${ }^{3}$ \\ Ashour Michael ${ }^{6}$ \\ Teresa Faga ${ }^{6}$ \\ Egidio Bevacqua ${ }^{7}$ \\ Federica Jiritano (D) $^{7}$ \\ Giuseppe Fliberto Serraino ${ }^{7}$ \\ Pasquale Mastroroberto ${ }^{7}$ \\ Michele Provenzano ${ }^{8}$ \\ Michele Andreucci ${ }^{6}$
}

'Interuniversity Center of Phlebolymphology (CIFL), "Magna Graecia” University, Catanzaro, Italy; ${ }^{2}$ Department of Surgical and Medical Sciences, University Magna Graecia of

Catanzaro, Viale Europa, Catanzaro, 88100,

Italy; ${ }^{3}$ Department of Public Health, University

of Naples "Federico II", Naples, Italy;

${ }^{4}$ Department of Public Health and Infectious

Disease, "Sapienza" University of Rome, Roma,

00185, Italy; ${ }^{5}$ Department of Molecular

Medicine and Medical Biotechnology, University

Federico II of Naples, Naples, Italy;

${ }^{6}$ Department of Health Sciences, "Magna

Graecia" University, Catanzaro, Italy

${ }^{7}$ Department of Experimental and Clinical

Medicine, University of Catanzaro, Catanzaro,

88100 , Italy; ${ }^{8}$ Department of Medical and Surgical

Sciences, University Magna Graecia of Catanzaro,

Viale Europa, Catanzaro, 88100, Italy

*These authors contributed equally to this work

Correspondence: Raffaele Serra Department of Surgical and Medical Sciences, Interuniversity Center of Phlebolymphology (CIFL), International Research and Educational Program in

Clinical and Experimental Biotechnology,

University Magna Graecia of Catanzaro,

Viale Europa, Catanzaro, 88100, Italy

Tel +3909613647380

Email rserra@unicz.it

\begin{abstract}
Chronic kidney disease (CKD) is a clinical condition characterized by high morbidity and mortality. Globally, CKD is also increasing in prevalence and incidence. The two principal kidney measures namely estimated glomerular filtration rate (eGFR) and albuminuria have been found to be predictors of renal and cardiovascular $(\mathrm{CV})$ endpoints including peripheral artery disease (PAD). The prevalence of PAD was increased in CKD patients and, particularly, in patients with more severe CKD stages. Despite the fact that revascularization strategies are suitable in CKD patients in similar fashion to non-CKD patients, few CKD patients underwent these procedures. In fact, if it is true that revascularization improves prognosis in PAD patients irrespective of baseline eGFR, it was also demonstrated that CKD patients, who underwent revascularization, were at higher risk for amputations, mortality, reintervention and perioperative complications. With the present review article, we have examined the association between CKD, PAD and peripheral revascularization highlighting data about epidemiology, pathophysiologic mechanisms, and results from previous observational and intervention studies. We have also examined the future perspectives and challenges of research around the association between CKD and PAD.
\end{abstract}

Keywords: chronic kidney disease, CKD, peripheral artery disease, PAD, ESKD, amputations, albuminuria

\section{Introduction}

Chronic kidney disease (CKD) is a chronic condition that can be diagnosed through the presence of a reduction in estimated Glomerular Filtration Rate (eGFR) $<60 \mathrm{~mL} / \mathrm{min} /$ $1.73 \mathrm{~m}^{2}$ and/or an increase in urine albumin excretion, namely albuminuria $>30 \mathrm{mg} / \mathrm{g}$ or $30 \mathrm{mg} / 24 \mathrm{~h}$ and/or by the presence of abnormalities in kidney structures persisting for at least 3 months. ${ }^{1,2}$ The eGFR is considered the principal measure of kidney function, whereas albuminuria is a well-assessed marker of kidney damage, being expression of alterations that may occur in any kidney structure, such as the glomerulus or the renal tubule. ${ }^{3}$ The presence of CKD exposes patients to an enhanced risk of several "hard" outcomes, so defined because they are associated with a major change in the patients' quality of life and in their long-term prognosis. CKD patients have, indeed, an increased risk for CKD progression to the End-Stage-Kidney-Disease (ESKD), which is the most severe phase of $\mathrm{CKD}$ requiring the recurrence to substitutive treatments, such as dialysis or kidney transplantation, and have an increased risk for cardiovascular (CV) events too. ${ }^{4}$ Several studies have explored the risk factors for CKD progression/ESKD and reporting 
that, among others, albuminuria, eGFR, serum phosphate levels, presence of diabetes, hemoglobin levels, age and male gender are strong predictors of the CKD outcomes. ${ }^{5}$ In the past few decades, preclinical and clinical research had also focused on assessing the risk factors and determinants for $\mathrm{CV}$ risk in CKD patients. ${ }^{6}$ Overall, the previous studies have prompted the Scientific Community to implement the development and validation of reliable biomarkers of $\mathrm{CV}$ risk in patients with $\mathrm{CKD}$, testifying that the risk stratification of $\mathrm{CKD}$ patients in terms of $\mathrm{CV}$ prognosis has not completely achieved yet. ${ }^{7-10}$ The major problem is represented by the fact that CV endpoint can encompass a wide spectrum of events, including fatal and non-fatal myocardial infarction (MI), heart failure (HF), stroke, arrhythmias, and peripheral artery disease (PAD). The pathogenesis, underlying these endpoints, varies between events, CKD stage and even between patients. Hence, prediction of $\mathrm{CV}$ risk in $\mathrm{CKD}$ still remains a great challenge for research. Furthermore, CKD affects the long-term prognosis of patients with coronary artery disease undergoing revascularization, which represents a non-negligible percentage of patients with $\mathrm{CV}$ damage. ${ }^{11}$ The aim of the present review article is to examine, among the listed $\mathrm{CV}$ events, the onset of Peripheral Artery Disease, given the importance, which is gaining, due to the novel acquisitions on both the pathogenetic pathways and therapeutic strategies.

\section{Global Dimension and Cardiovascular Risk in Patients with Chronic Kidney Disease}

The prevalence and incidence of CKD are both displaying an increasing trend over time. According to the Global Burden of Disease, the global prevalence of CKD increased by $86.95 \%$ from 1990 to 2016 and, similarly, the incidence of CKD rose by $88.76 \%$ in the same time frame. ${ }^{12}$ This increasing trend was found in all categories of socio-demographic index (SDI), albeit being higher in the low-SDI countries. National Registries reported a variable prevalence of CKD. In the United States (US) population of the National Health and Nutrition Examination Survey (NHANES), prevalence of CKD was of $13.1 \%$ overall and a prevalence $\geq 10 \%$ was also reported in Canada, Australia, China and the Netherlands. ${ }^{13}$ When taken together, these data show a non-trivial prevalence of CKD in the general population. Moreover, the severity of the problem is even enhanced by the prevalence and incidence of CV disease in CKD patients. In several insurance-based US population, mainly including elderly subjects suffering from CKD and diabetes, the incidence of atherosclerotic events and death overcame the one of ESKD. ${ }^{14,15}$ Among the population of CKD patients referred to Nephrologist, a tertiary care setting, the prevalence of history of $\mathrm{CV}$ disease (defined as the positive anamnesis for an episode of $\mathrm{MI}$, stroke, HF, PAD) rose from $30 \%$ to $50 \%$ in the cohort of MASTERPLAN, Chronic Renal Impairment in Birmingham (CRIB), African Americans Study (AASK) and Italian CKDMulticohort. ${ }^{16-19}$ In the CKD-Multicohort, which enrolled 3.957 CKD patients from multiple diagnoses referred to 128 Italian Renal Clinics, 34\% of them had CVD with the following distribution: $15.0 \% \mathrm{MI}, 6.0 \%$ stroke, $15.1 \% \mathrm{PAD}, 6.5 \%$ HF and $10.0 \%$ arrhythmias. ${ }^{19}$ On the Global Scale, an analysis of the Global Burden of Disease targeted CKD cohorts found that more than half of the total deaths' amount in these subjects were due to $\mathrm{CV}$ fatal events. $^{20}$

In a meta-analysis of more than 600.000 subjects of general population and high-risk populations derived from the CKD-Prognosis Consortium (in this large population, high-risk subjects were those with diabetes or CKD), Matsushita and colleagues found that the two principal parameters used to diagnose CKD, ie, albuminuria and eGFR were significantly associated with the development of $\mathrm{CV}$ events (defined as CV mortality, coronary heart disease, stroke and HF). ${ }^{6}$ Intriguingly, the prediction ability of those parameters was equal or stronger than that provided by traditional CV risk factors, such as smoking habit or blood pressure levels or LDL cholesterol levels. Several hypotheses have been claimed to explain the cause-effect relationship between kidney measures and CV risk. Albuminuria is considered a biomarker of endothelial dysfunction. ${ }^{6,21}$ Across the endothelium, albuminuria causes both structural (mainly to the endothelial glycocalyx) and functional alterations, such as the increase in vascular pressure. Across the kidney, albuminuria exerts alterations of the glomerulus and also has a direct toxic effect on renal tubules, amplifying proinflammatory and pro-fibrotic pathways that lead to kidney impairment over time. Moreover, as a vicious circle, the development of CKD per se contributes to increase $\mathrm{CV}$ risk via the presence of risk factors, such as inflammatory stimuli, volume expansion and uremic milieu. ${ }^{22}$ Thus, it has been hypothesized that those pathophysiological mechanisms are shared between CKD and CV disease.

\section{Peripheral Artery Disease in Chronic Kidney Disease}

With respect to PAD, several studies have demonstrated that patients with $\mathrm{CKD}$ have an increased risk of 
developing PAD. ${ }^{23,24}$ Peripheral artery disease is defined as the atherosclerotic lesions of peripheral arteries and differs from the acronymous PVD (peripheral vascular disease) which refers to the atherosclerotic lesions occurring in different vascular territories. ${ }^{25}$ Data from the US NHANES have reported that prevalence of PAD in patients with diabetes was 3-fold higher than those without diabetes, whereas the risk of PAD increased by 6.5 times in patients with eGFR $<60$ as compared with eGFR $\geq 60 \mathrm{~mL} / \mathrm{min} / 1.73 \mathrm{~m}^{2} .^{26}$ The risk of PAD increases for both patients with severe CKD and for those with mildmoderate CKD. Peripheral artery disease is defined as a chronic pathologic process due to atherosclerosis, which involves mainly the arteries providing flow to lower extremities. ${ }^{27}$ Risk of PAD in patients with CKD was confirmed even after adjusting the association for potential cofounders. $^{28,29}$ In the Atherosclerosis Risk in Communities (ARIC) cohort, enrolling patients who were likely to develop CKD or with $\mathrm{CKD}$, incidence of PAD, defined as ankle-brachial index $<0.9$, new intermittent claudication, or PAD-related hospitalizations, was higher in CKD patients after accounting for age, gender, race and presence of $\mathrm{CV}$ risk factors. ${ }^{29}$ Likewise, to other $\mathrm{CV}$ clinical events, the onset of PAD is strongly associated with the individual levels of eGFR and albuminuria. In a large meta-analysis of more than 800.000 subjects included in the CKD-Prognosis Consortium, risk for developing PAD increased, using the threshold of $95 \mathrm{~mL} /$ $\mathrm{min} / 1.73 \mathrm{~m} 2$, by $22 \%$ for eGFR of $45 \mathrm{~mL} / \mathrm{min}$ and by 2-fold for eGFR of $15 \mathrm{~mL} / \mathrm{min}^{30}$ The risk trend showed a similar magnitude when the effect of increasing albuminuria was tested. In fact, as compared with an albuminuria level of $5 \mathrm{mg} / \mathrm{g}$, risk raised by $50 \%$ for albuminuria of $30 \mathrm{mg} / \mathrm{g}$ and by about 2-fold for albuminuria of $300 \mathrm{mg} / \mathrm{g}$. All these data lead to think that there is an exponential association between decreasing eGFR/increasing albuminuria and PAD. Other traditional risk factors play an additional role in determining PAD in CKD patients. Among them, smoking habit and arterial hypertension have shown to have a wide and consistent relationship with vascular diseases and PAD. ${ }^{31,32}$ Furthermore, the incidence of PAD in CKD patients was associated with age, with a $28 \%$ risk increase by 10 years of age. ${ }^{33}$ Among the traditional correlates of PAD, male gender remains a significant predictor of PAD in patient with $\mathrm{CKD}{ }^{34}$ Being male conferred a $40 \%$ increased probability of developing PAD in this population. The presence of PAD affects individual prognosis and quality of life over time.
In an observational study enrolling more than 400.000 patients referred at the Manitoba Centre for Health Policy in Manitoba (Canada), the presence of PAD was more common in patients with CKD than in those without it, and the combination of PAD and CKD characterized the subgroup of patients at highest risk for lower-limb complications, CV events and mortality. ${ }^{35}$ Even more importantly, the presence of PAD alone was associated to a poorer prognosis, as compared to the presence of other $\mathrm{CV}$ diseases (eg, stroke, MI) without PAD. ${ }^{36}$ All these evidences can demonstrate the importance of an early detection and treatment of PAD in CKD patients. A further effort should be aimed at improving awareness of PAD among both clinicians and patients. ${ }^{37}$

\section{Revascularization for Peripheral Artery Disease: State of Art}

PAD is traditionally classified with two principal systems: the Rutherford classification, which is based on 7 risk categories (from 0 to 6), and the Fontaine classification, this latter being graded from Stage I to IV (Table 1). ${ }^{38,39}$ Both classifications include stages of increasing clinical and prognostic PAD severity. Another classification that is rapidly supplanting the Rutherford and Fontaine scores particularly in CKD patients undergoing renal replacement therapy. ${ }^{40}$ In fact, the WIfI classification provides more insights into the outcomes associated to each operative treatment. $^{41}$ The WIfI classification attributes a score to wound (W), ischemia (I), foot infection (f) and a combination of these scores allows to reach a unique categorization into meaningful clinical stages (depicted in Table 1). The initial therapeutic strategy of PAD consists in reinforcing preventive measures against adverse $\mathrm{CV}$ events. ${ }^{42}$ In particular, smoking cessation and exercise training have shown to have a good influence in stabilizing or even relenting the progression of claudication symptoms. ${ }^{43}$ Other measures are the improvement of antihypertensive, lipid-lowering and antiplatelet treatments as well as the reduction in patient's body weight. Several specific medications are indicated in CKD patients at increased risk for PAD. Antiplatelet treatments such as aspirin or clopidogrel have shown to reduce cardiovascular events in CKD and are thus recommended in absence of contraindications. ${ }^{44,45}$ Lipid lowering agents, namely statins and/or ezetimibe have shown to reduce cardiovascular risk and PAD risk in CKD patients, irrespective of the basal level of LDLcholesterol and should be started in these high-risk 
Table I Rutherford, Fontaine and WIfl Classifications of PAD

\begin{tabular}{|c|c|c|c|c|c|c|c|}
\hline \multirow{2}{*}{$\begin{array}{l}\text { Grade } \\
0\end{array}$} & \multirow{2}{*}{$\frac{\text { Category }}{0}$} & \multirow{2}{*}{$\begin{array}{c}\text { Rutherford } \\
\text { Asymptomatic. Absence of } \\
\text { hemodynamically significant } \\
\text { occlusive disease }\end{array}$} & \multirow{2}{*}{$\frac{\text { Grade }}{1}$} & \multirow{2}{*}{$\begin{array}{c}\text { Fontaine } \\
\text { Asymptomatic, } \\
\text { incomplete } \\
\text { blood vessel } \\
\text { obstruction }\end{array}$} & \multicolumn{3}{|r|}{ WIfI } \\
\hline & & & & & $\begin{array}{c}\text { Risk of } \\
\text { amputation }\end{array}$ & $\begin{array}{l}\text { Proposed } \\
\text { clinical } \\
\text { stages }\end{array}$ & WIfl spectrum score \\
\hline & I & Mild claudication & ॥ & $\begin{array}{l}\text { Mild } \\
\text { claudication, } \\
\text { limb pain }\end{array}$ & Very low & Stage I & $\begin{array}{c}\text { W0 I0 fl0, I W0 II flo WI } 10 \mathrm{fl0} \text {, } \\
\text { WI II fl } 0\end{array}$ \\
\hline \multirow[t]{2}{*}{ I } & 2 & Moderate claudication & IIA & $\begin{array}{c}\text { Claudication }> \\
200 \text { meters }\end{array}$ & Low & Stage 2 & $\begin{array}{c}\text { W0 I0 fl2 W0 II flI W0 I2 fl0, I } \\
\text { Wo I3 fl0 WI I0 fl2 WI II flI } \\
\text { WIILfio W2 I0 fl0/I }\end{array}$ \\
\hline & 3 & Severe claudication & IIB & $\begin{array}{c}\text { Claudication }< \\
200 \text { meters }\end{array}$ & Moderate & Stage 3 & $\begin{array}{c}\text { W0 I0 fl3 W0 I2 flI,2 W0 I3 flI,2 } \\
\text { WI I0 fl3 WI II fl2 WI I2 flI WI } \\
\text { I3 fl0, I W2 } 10 \mathrm{fl} 2 \mathrm{~W} 2 \text { I I fl0, I W2 } \\
I 2 \text { fi0 W3 } 10 \text { fi0, I }\end{array}$ \\
\hline ॥ & 4 & Ischemic rest pain & III & $\begin{array}{l}\text { Rest pain, } \\
\text { particularly in } \\
\text { the feet }\end{array}$ & High & Stage 4 & $\begin{array}{c}\text { W0 II,2,3 fl3 WI II fl3 WI I2,3 } \\
\text { fl2,3 W2 I0 fi3 W2 II fl2,3 W2 I2 } \\
\text { fil,2,3 W2 I3 fl0, I,2,3 W3 I0 fl2,3 } \\
\text { W3 II,2,3 fl0, I,2,3 }\end{array}$ \\
\hline \multirow[t]{2}{*}{ III } & 5 & $\begin{array}{c}\text { Minor tissue loss. } \\
\text { Nonhealing ulcer, focal } \\
\text { gangrene with diffuse pedal } \\
\text { ischemia }\end{array}$ & IV & $\begin{array}{l}\text { Limb necrosis } \\
\text { and/or } \\
\text { gangrene }\end{array}$ & & & \\
\hline & 6 & $\begin{array}{l}\text { Major tissue loss namely } \\
\text { extending above trans- } \\
\text { metatarsal level, functional } \\
\text { foot no longer salvageable }\end{array}$ & & & & & \\
\hline
\end{tabular}

patients. ${ }^{46,47}$ If the medical therapies and physical exercise can begin in the first stages of PAD, they warrant a durable stability of PAD. ${ }^{48}$ The intermediate step, recommended for patients who have not experienced any improvement in their clinical symptoms, is the treatment with cilostazol. Cilostazol is a phosphodiesterase inhibitor that acts by suppressing platelet aggregation. It also has a direct arterial vasodilator. ${ }^{49}$ In previous trials, cilostazol showed to be able to significantly increase maximal walking distances and pain-free walking distances in patients with moderate-tosevere claudication. ${ }^{50}$ Nevertheless, in several cases, conservative treatment does not represent the best choice. In fact, patients, who do not respond adequately to medical treatment/exercise training as well as patients with claudication symptoms impact the quality of life, are eligible for revascularization (Figure 1). Revascularization for PAD should be executed via surgical or percutaneous techniques or via combination of both of them. Surgical revascularization encompasses bypass grafts and endarterectomy, whereas percutaneous treatment should be executed via angioplasty, atherectomy and stenting in the most cases. The choice of the type of intervention is influenced by multiple factors. To facilitate clinical decision making, the Inter-Society Consensus for the Management of Peripheral Artery Diseases (TASC II) has provided a classification of PAD based on the differential outcomes after percutaneous or surgical treatment. ${ }^{24}$ The factors considered for risk stratification have mainly been the location and extent of obstructive lesion and the patient's baseline risk profile. Overall, TASC II classification comprises four types of lesions (namely A, B, C, D) foriliac, femoral, and popliteal lesions. Type A and $\mathrm{B}$ lesions have an excellent prognosis after endovascular treatment. Conversely, type $\mathrm{C}$ lesions have a more favorable outcome after surgical open intervention and thus surgery should be preferred unless the baseline risk contraindicates this procedure. Type 


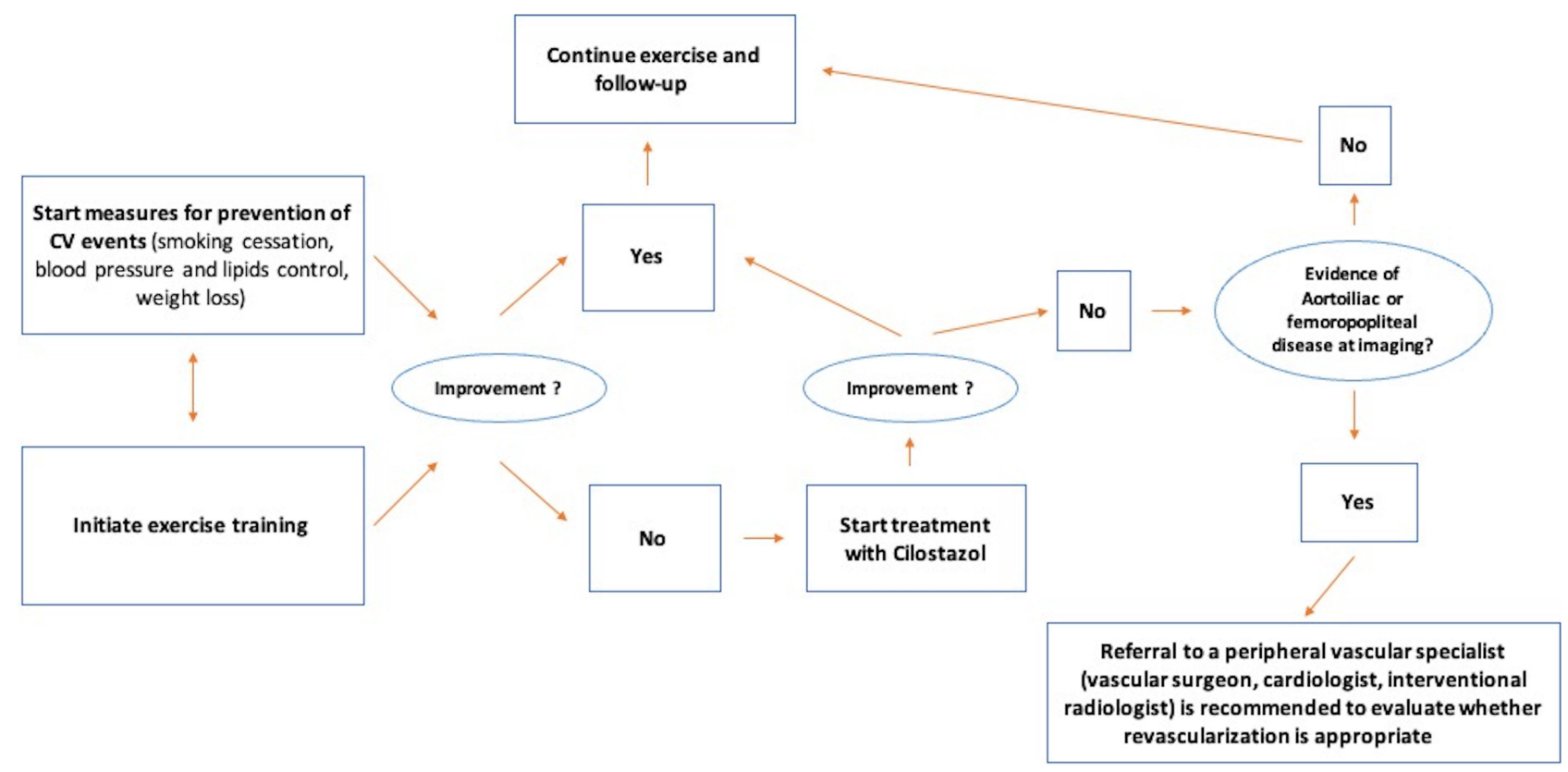

Figure I Algorithm for the management of PAD in CKD patients.

D lesions are not well treated by endovascular procedures and are therefore must be referred for surgical repair, even if, due to the improvement of techniques and materials, percutaneous approach to complex lesions has shown good mid- and long-term results. ${ }^{51}$ The location of occlusive lesions is another important element to consider during treatment selection, since endovascular treatment is associated with better outcomes when the occlusion is located in aorto-iliac rather than infra-inguinal portion. ${ }^{52}$ With respect to baseline individual risk, several risk factors should be carefully evaluated, including presence of coronary heart disease, diabetes, kidney function impairment and evaluation of nutritional status. Several risk factors predict poor prognosis of PAD in patients with CKD. Among them, the African American race has been found associated with an increased risk for failure after lower limb revascularization. ${ }^{53}$ Several risk prediction models, computing the in-hospital and long-term individual risk, have been also developed. ${ }^{54,55}$

\section{Why Does CKD Affect the Management and Prognosis of PAD?}

One of the crucial points of the link between CKD and PAD is that the frequency of PAD increases as the severity of CKD increases. ${ }^{56}$ The prevalence of PAD exceeded $30 \%$ in patients with stage 5CKD in several studies. ${ }^{57,58}$ Such a trend has a reflection from a "public health" perspective, since patients with CKD and PAD showed an increase in both length of in-hospital stay and health care costs. CKD patients with PAD are also at increased risk for in-hospital death, independently on the severity of PAD. ${ }^{59}$ Furthermore, it has been demonstrated that CKD is associated with the onset of a more severe stage of PAD, such as chronic limb ischemia (CLI). ${ }^{59}$ Hence, the assessment of an early diagnosis of claudication as well as the prevention and treatment of CLI represents very important steps in CKD patients. Following the current recommendations, indications for revascularization in CKD patients with PAD did not differ from those applied to patients without CKD. ${ }^{60}$ Such an attitude is compatible with the result of a large study enrolling 351 patients who underwent either surgical or percutaneous revascularization for CLI. $^{61}$ This analysis has been assessed on patients with different levels of renal function impairment and showed that revascularization conferred benefits in terms of amputation-free survival and limb salvage in both CKD and non-CKD patients. Many other studies, specifically carried out in CKD populations, reported that endovascular and surgical revascularization are both effective in reducing patients' mortality and amputation rate, with the surgical strategy being more advantageous in the long term (beyond 2 years follow-up). ${ }^{62,63}$ What can be considered as a "clinical paradox" is that, despite the high prevalence of PAD in CKD patients, these high-risk patients undergo fewer revascularization procedures as compared to patients 
without CKD. In a report of the Veterans Affairs National Patient Care Database, patients with eGFR between 30 and $59 \mathrm{~mL} / \mathrm{min} / 1.73 \mathrm{~m} 2$ had a lower probability $(16 \%)$ to undergo revascularization, being this probability reduced of about $50 \%$ in patients with an eGFR of $15-29 \mathrm{~mL} / \mathrm{min} /$ $1.73 \mathrm{~m} 2$ and even of about $70 \%$ in CKD patients in ESKD. $^{64}$ Similar findings were extrapolated from a European database, thus testifying that this trend is generalizable, irrespective of the geographic area. ${ }^{65}$ This low tendency in referring CKD patients to intensive care treatments for PAD can be interpreted considering other studies suggesting high risk for complications and worse outcomes after revascularization. ${ }^{42}$ In patients with ESKD the risk for limb loss after surgical revascularization was about 5-fold higher when compared to those with an earlier stage of CKD, despite a similar revascularization rate. ${ }^{66}$ Similarly, an augmented risk of amputation and reintervention has been reported in ESKD patients undergoing percutaneous revascularization. ${ }^{67}$ Another factor that may influence treatment decisions is the patients with both PAD and CKD, who undergo revascularization, are also subject to develop Contrast-induced acute kidney injury (C-AKI). The risk of C-AKI is mainly caused by the fact that patients are selected for revascularization practice angiography before the procedure. Furthermore, in the vast majority of cases, this diagnostic exam is not executed together with measures that prevent C-AKI, such as the use of low contrast volume, the introduction of statins or $\mathrm{n}$-acetylcysteine and the meticulous control of intravascular volume in order to avoid. ${ }^{68-70}$ The presence of C-AKI and $\mathrm{CKD}$, and particularly the concomitant presence of both conditions, was associated with about a 3 -fold higher risk of death in CKD patients after revascularization. ${ }^{60}$ With respect to perioperative complications, CKD patients were found at increased risk of respiratory insufficiency, intubation, bleeding and infectious. ${ }^{60,71}$

\section{Potential Links Between CKD and PAD}

CKD is a chronic condition, which can be caused by many disparate etiologies. ${ }^{2}$ Moreover, albeit several risk factors are able to predict the future outcomes in patients with different degrees of renal impairment, the prognostic weight of each factor varies between CKD stages and even between patients with similar severity of kidney function impairment. ${ }^{72}$ This means that the CKD status perfectly fits the concept of "heterogeneity" with regard to both etiology and prognosis. Notwithstanding, CKD shows, regardless of the different etiologies, common pathophysiologic patterns. First of all, CKD is associated with pro-inflammatory and pro-fibrotic stimuli. ${ }^{73}$ Tissue expression as well as circulating levels of inflammatory mediators, such as interleukins (IL-1, IL-6), tumor necrosis factor (TNF)- $\alpha$, monocyte chemoattractant protein-1 (MCP-1), C-reactive protein and kidney injury molecule-1 (KIM-1), are altered in patients with $\mathrm{CKD}^{74}$ Among inflammatory markers, some of them, such as MCP-1 and KIM-1, have shown to improve prediction of $\mathrm{CKD}$ progression beyond considering traditional risk factors. ${ }^{75}$ The inflammatory status in CKD worsens both the vascular calcification and endothelial dysfunction. ${ }^{76}$ The vascular-endothelial dysfunction in CKD has been widely investigated and described in previous studies. ${ }^{77,78}$ It consists of a mosaic of alterations, including increased intimamedia thickness and vascular stiffness that is determined by inflammation, oxidative stress and other risk factors typical of CKD (eg, hyperphosphatemia) ${ }^{78}$ Imbalances of extracellular matrix (ECM) also contribute to the inflammatory status and to the development of PAD in CKD patients. Experimental and human studies testified that both blood and urine levels of matrix metalloproteinases (MMPs) are enormously unregulated in CKD patients. ${ }^{79}$ Matrix metalloproteinase-3 (MMP-3), MMP-7 and MMP-9 have a direct pro-inflammatory effect by increasing mononuclear cell activation and proliferation. ${ }^{80,81}$ Furthermore, MMP-3 promotes epithelial-to-mesenchymal transition, the process through which epithelial cells acquire the fibroblastic phenotype that anticipates tissue fibrosis. ${ }^{82}$ The imbalance in MMPs has also been associated with the development of PAD. A number of MMPs (MMP-1, -2, -3, -9, -14 and the tissue inhibitor of metalloproteinase-1 also called TIMP-1) have shown to accelerate the atherosclerotic process. ${ }^{83} \mathrm{In}$ the context of atherosclerotic plaque, MMPs regulate the formation of the fibrous cap and increase the amount of inflammation too. ${ }^{84}$ Increased plasma levels of MMP-1 and -8 have been associated to an increased risk for amputation in patients undergoing surgical revascularization for PAD. ${ }^{85}$ Additionally, CKD is characterized by the reduced excretion of substrates that can damage various cells and systems and that are thus defined "uremic toxins". The indolic uremic toxins indoxyl sulfate and indoxyl acetate have a prothrombotic effect that is determined by their effect on both extrinsic coagulation pathway and on platelet activation. ${ }^{85,86} \beta 2$-microglobulin, a protein expressed on the surface of immune cells, has shown to improve the prediction of $\mathrm{CV}$ events in $\mathrm{CKD}$ patients even after 
accounting for their eGFR levels and, in particular, it has been linked to the onset of PAD in these patients. ${ }^{87-90}$ Thus, it can be hypothesized that the link between CKD and PAD is a mix of multiple factors, including the inflammation, oxidative stress, imbalance in ECM composition that are associated with PAD and amplified by the concomitant presence of CKD. This can partially explain the results of an autoptic study demonstrating that the severity of atherosclerotic disease increases going from mild to severe CKD stages independently of other CV comorbidities and even in absence of diabetes. ${ }^{91}$ Nevertheless, future mechanistic studies are needed to shed light on the exact molecular mechanisms leading from CKD to PAD. A summary of the main key-messages of the previous sections of the manuscript is reported in Table 2.

\section{Peripheral Artery Disease in Chronic Kidney Disease: Future Challenges}

The management of CKD patients has always been focused on slowing CKD progression and reducing $\mathrm{CV}$ and all-cause mortality risk too. To this aim, the past two decades have been signed by the implementation of clinical trials testing the efficacy of novel drugs on cardiovascular and renal protection in CKD patients. ${ }^{72}$ This was a really great effort in clinical research. A first crucial step was the demonstration that drugs inhibiting the Renin-Angiotensin-AldosteroneSystem (RAASi) are effective in reducing both the eGFR decline over time and CV risk. ${ }^{92,93}$ Despite the implementation of these agents in clinical practice, nowadays the residual $\mathrm{CV}$ risk (namely the risk that remains after the use of maximum tolerated dose of RAASi) is still very high. Reasons for this phenomenon has to be found, at least in part, in the great individual variability in response to nephroprotective treatments. A further step forward has been done in 2020 with the publication of large intervention studies, which demonstrated the strong efficacy on cardio-renal protection of other pharmacologic agents, ie the sodium-glucose -cotransporter 2 inhibitors (SGLT2is), the selective antagonists of endothelin receptors type A (ERA) and the novel nonsteroidal mineral receptor antagonists (MRA) ${ }^{94-98}$ These novel drug classes provided encouraging findings, especially in patients with both CKD and type 2 diabetes, since they warrant a significant $\mathrm{CV}$ protection when added to the standard-of-care (RAASi). Moreover, the development of individual risk prediction models in CKD patients have contributed to detect with more accuracy CKD patients at high-risk for worse CV outcomes that need a stricter monitoring and intensive care. However, in the majority of cases these scores have been built considering $\mathrm{CV}$ outcome as a composite of multiple endpoints including MI, HF or PAD. What we have learned from the current Literature is

Table 2 Summary of the Principal Aspects of the Association Between CKD and PAD

\begin{tabular}{|c|c|}
\hline & Key-Messages \\
\hline Epidemiology & $\begin{array}{l}\text { - Chronic kidney disease (CKD) is associated with an increased risk for cardiovascular (CV) diseases, including } \\
\text { Peripheral Artery Disease (PAD). } \\
\text { - Risk of PAD is about } 6.5 \text { fold higher in patients with CKD }\left(e G F R<60 \mathrm{~mL} / \mathrm{min} / 1.73 \mathrm{~m}^{2}\right) \text { as compared with those } \\
\text { without CKD. } \\
\text { - There is an association between CKD and PAD even after adjustment for the traditional CV risk factors. }\end{array}$ \\
\hline Risk factors & $\begin{array}{l}\text { - Kidney measures, albuminuria and eGFR levels are significant predictors of the risk of PAD in CKD patients. } \\
\text { - Traditional CV risk factors, such as smoking habit and increased blood pressure, play a significant role beyond the } \\
\text { kidney measures in determining PAD in CKD patients. } \\
\text { - Risk of PAD is increased in more severe stage of CKD (ie Stage } 4 \text { and 5). }\end{array}$ \\
\hline Pathogenesis & $\begin{array}{l}\text { - } \text { CKD is a condition characterized by an inflammatory status which exacerbates vascular damage. } \\
\text { - Alterations of extracellular matrix, which are present in CKD, contribute to impair inflammation and accelerate } \\
\text { atherosclerotic process. } \\
\text { - Uremic toxins play a direct role in determining vascular damage and PAD. }\end{array}$ \\
\hline $\begin{array}{l}\text { Management and } \\
\text { Prognosis }\end{array}$ & $\begin{array}{l}\text { - Revascularization is indicated in patients with CKD and severe PAD with symptomatic and limiting claudication } \\
\text { - Both percutaneous and surgical revascularizations improve the prognosis of CKD patients in term of amputation rate } \\
\text { and their mortality. } \\
\text { - CKD patients show higher risk for perioperative complications after revascularization as compared with non-CKD } \\
\text { patients. }\end{array}$ \\
\hline
\end{tabular}


that each of this $\mathrm{CV}$ outcome has a proper risk profile. This is particularly true when considering that CKD is per se an heterogeneous condition. Hence, $\mathrm{CV}$ risk prediction remains suboptimal. In the specific context of PAD, improving risk stratification of patients, that is translated in clinical practice into finding CKD patients at high risk of developing PAD, is an urgent need, indeed. Recently, the International Society of Nephrology (I.S.N.) has started a program entitled "closing the gaps" with the aim of encouraging the implementation of novel biomarkers of CV risk in CKD. ${ }^{10}$ The I.S.N. outlined two important points, namely the need to find biomarkers for specific CV endpoints and to build large international databases that allow to generalize the results to different races and patients. The final result may be the redefinition of guidelines for PAD management in CKD. In fact, if it is clear that revascularization improved outcomes irrespectively of CKD severity, it has been also demonstrated that CKD patients are more likely to develop both short-term and longterm complications after revascularization. Hence, the careful detection of CKD patients at increased risk for PAD would be extremely important for their management and prognosis. Similarly, the current management of PAD cannot differentiate the indications for percutaneous versus surgical revascularization among $\mathrm{CKD}$ and non-CKD patients. However, PAD in CKD is characterized by its more distal localization and is associated to a greater degree of vascular calcification and stiffness. For this reason, research should also focus in the future in realizing devices specific for lesions present in CKD patients. Furthermore, it should be emphasized that the observed limited benefit for CKD patients differs from that observed in patients without $\mathrm{CKD}$. Hence, the risk benefit ratio for a given procedure may be different although this is not yet well demonstrated. The decision to proceed with limb-preservation strategies therefore hinges upon the ability to properly risk-stratify patients. This risk stratification may in fact be different for patients suffering from CKD and chronic limb threatening ischemia. Thus, clinical trials comparing the outcome of these different intervention strategies, specifically conducted in CKD setting, are eagerly expected. ${ }^{99}$ Further experimental studies should also flank the clinical research by revealing more molecular and pathophysiologic mechanisms of PAD in patients with different degrees of kidney impairment. ${ }^{42}$ Another important step for research, and for clinical practice as well, is represented by the need for a multidisciplinary approach to the patient with CKD and PAD. In this case, the multidisciplinary model of care, which may encompass Vascular Surgeon, Nephrologist, Cardiologist, Radiologist may help to reach a better and earlier care for these highrisk patients.

\section{Conclusions}

In conclusion, $\mathrm{CKD}$ is associated with a wide spectrum of $\mathrm{CV}$ diseases including PAD. The prevalence of PAD is high in CKD patients and increases moving from mild to severe degrees of kidney function impairment. The surgical or percutaneous revascularizations have shown to improve prognosis in CKD patients. Novel studies would be very helpful to both refine risk stratification of patients with CKD and PAD and help clinicians decide which type of intervention may be the best for each patient.

\section{Author Contributions}

All authors contributed to data analysis, drafting or revising the article, gave final approval of the version to be published, agreed to the submitted journal, and agreed to be accountable for all aspects of the work.

\section{Funding}

This research received no specific grant from any funding agency in the public, commercial or not-for-profit sectors.

\section{Disclosure}

The Authors declare that there is no conflict of interest.

\section{References}

1. Chapter 4: Other complications of CKD: CVD, medication dosage, patient safety, infections, hospitalizations, and caveats for investigating complications of CKD. Kidney Int Suppl. 2013;91-111. doi:10.1038/ kisup. 2012.67

2. De Nicola L, Provenzano M, Chiodini P, et al. Independent role of underlying kidney disease on renal prognosis of patients with chronic kidney disease under nephrology care. PLoS One. 2015;10(5): e0127071. doi:10.1371/journal.pone.0127071

3. Provenzano M, Garofalo C, Chiodini P, et al. Role of proteinuria in clinical research: for each old-answer, a new key-question. Recent Prog Med. 2020;111(2):74-81.

4. Levey AS, Coresh J. Chronic kidney disease. Lancet. 2012;379 (9811):165-180. doi:10.1016/S0140-6736(11)60178-5

5. Astor BC, Matsushita K, Gansevoort RT, et al. Lower estimated glomerular filtration rate and higher albuminuria are associated with mortality and end-stage renal disease. a collaborative meta-analysis of kidney disease population cohorts. Kidney Int. 2011;79 (12):1331-1340. doi:10.1038/ki.2010.550

6. Matsushita K, Coresh J, Sang Y, et al. Estimated glomerular filtration rate and albuminuria for prediction of cardiovascular outcomes: a collaborative meta-analysis of individual participant data. Lancet Diabetes Endocrinol. 2015;3(7):514-525. doi:10.1016/S22138587(15)00040-6

7. Ballew SH, Matsushita K. Cardiovascular risk prediction in CKD. Semin Nephrol. 2018;38(3):208-216. doi:10.1016/j.semnephrol. 2018.02.002 
8. Rangaswami J, Bhalla V, Blair JEA, et al. Cardiorenal syndrome: classification, pathophysiology, diagnosis, and treatment strategies: a scientific statement from the American Heart Association. Circulation. 2019;139 (16):e840- e878. doi:10.1161/CIR.0000000000000664

9. Provenzano M, Coppolino G, Faga T, et al. Epidemiology of cardiovascular risk in chronic kidney disease patients: the real silent killer Rev Cardiovasc Med. 2019;20(4):209-220.

10. Pena MJ, Stenvinkel P, Kretzler M, et al. Strategies to improve monitoring disease progression, assessing cardiovascular risk, and defining prognostic biomarkers in chronic kidney disease. Kidney Int Suppl. 2017;7(2):107-113. doi:10.1016/j.kisu.2017.07.005

11. Hayatsu Y, Ruel M, Sun LY. Renal insufficiency and severe coronary artery disease: should coronary artery bypass grafting, off-pump coronary artery bypass grafting or percutaneous coronary intervention be performed? Curr Opin Cardiol. 2019;34(6):645-649. doi:10.1097/HCO.0000000000000687

12. Xie Y, Bowe B, Mokdad AH, et al. Analysis of the global burden of disease study highlights the global, regional, and national trends of chronic kidney disease epidemiology from 1990 to 2016. Kidney Int. 2018;94(3):567-581. doi:10.1016/j.kint.2018.04.011

13. De Nicola L, Donfrancesco C, Minutolo R, et al. Prevalence and cardiovascular risk profile of chronic kidney disease in Italy: results of the 2008-12 National Health Examination Survey. Nephrol Dial Transplant. 2015;30(5):806-814. doi:10.1093/ndt/gfu383

14. Keith DS, Nichols GA, Gullion CM, et al. Longitudinal follow-up and outcomes among a population with chronic kidney disease in a large managed care organization. Arch Intern Med. 2004;164 (6):659-663. doi:10.1001/archinte.164.6.659

15. Patel UD, Young EW, Ojo AO, et al. CKD progression and mortality among older patients with diabetes. Am J Kidney Dis. 2005;46 (3):406-414. doi:10.1053/j.ajkd.2005.05.027

16. Van Zuilen AD, Van der Tweel I, Blankestijn PJ, et al. Multifactorial approach and superior treatment efficacy in renal patients with the aid of nurse practitioners. Design of The MASTERPLAN Study [ISRCTN73187232]. Trials. 2006;7(1):8. doi:10.1186/1745-6215-7-8

17. Landray MJ, Thambyrajah J, McGlynn FJ, et al. Epidemiological evaluation of known and suspected cardiovascular risk factors in chronic renal impairment. Am J Kidney Dis. 2001;38(3):537-546. doi:10.1053/ajkd.2001.26850

18. Norris K, Bourgoigne J, Gassman J, et al. Cardiovascular outcomes in the African American study of kidney disease and hypertension (AASK) trial. Am J Kidney Dis. 2006;48(5):739-751. doi:10.1053/j. ajkd.2006.08.004

19. Provenzano M, Chiodini P, Minutolo R, et al. Reclassification of chronic kidney disease patients for end-stage renal disease risk by proteinuria indexed to estimated glomerular filtration rate: multicentre prospective study in nephrology clinics. Nephrol Dial Transplant. 2020;35(1):138-147.

20. Thomas B, Matsushita K, Abate KH, et al. Global cardiovascular and renal outcomes of reduced GFR. J Am Soc Nephrol. 2017;28 (7):2167-2179. doi:10.1681/ASN.2016050562

21. Theilade S, Lajer M, Jorsal A, et al. Arterial stiffness and endothelial dysfunction independently and synergistically predict cardiovascular and renal outcome in patients with type 1 diabetes. Diabet Med. 2012;29(8):990-994. doi:10.1111/j.1464-5491.2012.03633.x

22. Provenzano M, Coppolino G, De Nicola L, et al. Unraveling cardiovascular risk in renal patients: a new take on old tale. Front Cell Dev Biol. 2019;3(7):314. doi:10.3389/fcell.2019.00314

23. Gerhard-Herman MD, Gornik HL, Barrett C, et al. Guideline on the management of patients with lower extremity peripheral artery disease: a report of the American college of cardiology/American heart association task force on clinical practice guidelines. Circulation. 2017;135(12):e726-e779.

24. Norgren L, Hiatt WR, Dormandy JA, et al. Inter-society consensus for the management of peripheral arterial disease (TASC II). $J$ Vasc Surg. 2007;45(Suppl S):S5-67.
25. Berger JS, Hochman J, Lobach I, et al. Modifiable risk factor burden and the prevalence of peripheral artery disease in different vascular territories. J Vasc Surg. 2013;58(3):673-81.e1. doi:10.1016/j. jvs.2013.01.053

26. Selvin E, Erlinger TP. Prevalence of and risk factors for peripheral arterial disease in the United States: results from the National health and nutrition examination survey, 1999-2000. Circulation. 2004;110 (6):738-743. doi:10.1161/01.CIR.0000137913.26087.F0

27. Creager MA. The crisis of vascular disease and the journey to vascular health: presidential address at the American Heart Association 2015 Scientific Sessions. Circulation. 2016;133 (24):2593-2598. doi:10.1161/CIR.0000000000000434

28. O'Hare AM, Vittinghoff E, Hsia J, et al. Renal insufficiency and the risk of lower extremity peripheral arterial disease: results from the heart and estrogen/progestin replacement study (HERS). J Am Soc Nephrol. 2004;15(4):1046. doi:10.1097/01.ASN.0000119574.27772.FD

29. Wattanakit K, Folsom AR, Selvin E, et al. Kidney function and risk of peripheral arterial disease: results from the atherosclerosis risk in communities (ARIC) study. J Am Soc Nephrol. 2007;18(2):629. doi:10.1681/ASN.2005111204

30. Matsushita K, Ballew SH, Coresh J, et al. Measures of chronic kidney disease and risk of incident peripheral artery disease: a collaborative meta-analysis of individual participant data. Lancet Diabetes Endocrinol. 2017;5(9):718-728. doi:10.1016/S22138587(17)30183-3

31. Staplin N, Haynes R, Herrington WG, et al. Smoking and adverse outcomes in patients with CKD: the study of heart and renal protection (SHARP). Am J Kidney Dis. 2016;68(3):371-380. doi:10.1053/j. ajkd.2016.02.052

32. Ninomiya T, Perkovic V; Blood Pressure Lowering Treatment Trialists' Collaboration. Blood pressure lowering and major cardiovascular events in people with and without chronic kidney disease: meta-analysis of randomised controlled trials. BMJ. 2013;347:f5680.

33. Jaar BG, Plantinga LC, Astor BC, et al. Novel and traditional cardiovascular risk factors for peripheral arterial disease in incident-dialysis patients. Adv Chronic Kidney Dis. 2007;14 (3):304-313. doi:10.1053/j.ackd.2007.04.005

34. Rajagopalan S, Dellegrottaglie S, Furniss AL, et al. Peripheral arterial disease in patients with end-stage renal disease: observations from the dialysis outcomes and practice patterns study (DOPPS). Circulation. 2006;114(18):1914-1922. doi:10.1161/ CIRCULATIONAHA.105.607390

35. Bourrier M, Ferguson TW, Embil JM, et al. Peripheral artery disease: its adverse consequences with and without CKD. Am J Kidney Dis. 2020;75(5):705-712. doi:10.1053/j.ajkd.2019.08.028

36. Bonaca MP, Nault P, Giugliano RP, et al. Low-density lipoprotein cholesterol lowering with evolocumab and outcomes in patients with peripheral artery disease: insights from the FOURIER Trial (Further cardiovascular outcomes research with PCSK9 inhibition in subjects with elevated risk). Circulation. 2018;137(4):338-350. doi:10.1161/ CIRCULATIONAHA.117.032235

37. Hishida M, Menez S, Matsushita K. Peripheral artery disease in CKD: anatomically peripheral but clinically central. Am J Kidney Dis. 2020;75(5):687-689. doi:10.1053/j.ajkd.2019.10.006

38. Rutherford RB, Baker JD, Ernst C, et al. Recommended standards for reports dealing with lower extremity ischemia: revised version. $J$ Vasc Surg. 1997;26(3):517-538. doi:10.1016/S0741-5214(97)70045-4

39. Hardman RL, Jazaeri O, Yi J, et al. Overview of classification systems in peripheral artery disease. Semin Intervent Radiol. 2014;31:378-388.

40. Mills JL Sr, Conte MS, Armstrong DG, et al.; Society for Vascular Surgery Lower Extremity Guidelines Committee The society for vascular surgery lower extremity threatened limb classification system: risk stratification based on wound, ischemia, and foot infection (WIfI). J Vasc Surg. 2014;59(1):220-34.e1-2. doi:10.1016/j. jvs.2013.08.003. 
41. Farchioni L, Gennai S, Giuliani E, et al. A prognostic risk score for major amputation in dialysis patients with chronic limb-threatening ischemia after endovascular revascularization. Int Angiol. 2021;40 (3):206-212; PMID: 33660496. doi: 10.23736/S0392-9590.21.04523-5

42. Arinze NV, Gregory A, Francis JM, et al. Unique aspects of peripheral artery disease in patients with chronic kidney disease. Vasc Med. 2019;24(3):251-260. doi:10.1177/1358863X18824654

43. Gerhard-Herman MD, Gornik HL, Barrett C, et al. 2016 AHA/ACC Guideline on the management of patients with lower extremity peripheral artery disease: a report of the American college of cardiology/ American heart association task force on clinical practice guidelines. Circulation. 2017;135(12):e726-e779.

44. Jardine MJ, Ninomiya T, Perkovic V, et al. Aspirin is beneficial in hypertensive patients with chronic kidney disease: a post-hoc subgroup analysis of a randomized controlled trial. J Am Coll Cardiol. 2010;56 (12):956-965. PMID: 20828648. doi:10.1016/j.jacc.2010.02.068

45. Clagett GP, Sobel M, Jackson MR, et al. Antithrombotic therapy in peripheral arterial occlusive disease: the seventh ACCP conference on antithrombotic and thrombolytic therapy. Chest. 2004;126(3):609S626S. PMID: 15383487. doi:10.1378/chest.126.3_suppl.609S

46. Baigent C, Landray MJ, Reith C, et al. The effects of lowering LDL cholesterol with simvastatin plus ezetimibe in patients with chronic kidney disease (Study of Heart and Renal Protection): a randomised placebo-controlled trial. Lancet. 2011;377(9784):2181-2192; PMID: 21663949; PMCID: PMC3145073. doi: 10.1016/S0140-6736(11) 60739-3

47. De Nicola L, Provenzano M, Chiodini P, et al.; SIR-SIN study group. Prognostic role of LDL cholesterol in non-dialysis chronic kidney disease: multicenter prospective study in Italy. Nutr Metab Cardiovasc Dis. 2015; 25(8):756-762. doi:10.1016/j. numecd.2015.04.001. PMID: 26026213.

48. Mazari FA, Gulati S, Rahman MN, et al. Early outcomes from a randomized, controlled trial of supervised exercise, angioplasty, and combined therapy in intermittent claudication. Ann Vasc Surg. 2010;24(1):69-79. doi:10.1016/j.avsg.2009.07.005

49. Reilly MP, Mohler ER 3rd. Cilostazol: treatment of intermittent claudication. Ann Pharmacother. 2001;35(1):48-56.

50. Thompson PD, Zimet R, Forbes WP, et al. Meta-analysis of results from eight randomized, placebo-controlled trials on the effect of cilostazol on patients with intermittent claudication. Am J Cardiol. 2002;90(12):1314-1319. doi:10.1016/S0002-9149(02)02869-2

51. Bracale UM, Giribono AM, Spinelli D, et al. Long-term results of endovascular treatment of TASC C and D aortoiliac occlusive disease with expanded polytetrafluoroethylene stent graft. Ann Vasc Surg. 2019;56:254-260. doi:10.1016/j.avsg.2018.07.060

52. Tendera M, Aboyans V; European Stroke Organisation. ESC Guidelines on the diagnosis and treatment of peripheral artery diseases: document covering atherosclerotic disease of extracranial carotid and vertebral, mesenteric, renal, upper and lower extremity arteries: the task force on the diagnosis and treatment of peripheral artery diseases of the European Society of Cardiology (ESC). Eur Heart J. 2011;32(22):2851-2906.

53. Ambur V, Park P, Gaughan JP, et al. The impact of chronic kidney disease on lower extremity bypass outcomes in patients with critical limb ischemia. J Vasc Surg. 2019;69(2):491-496. doi:10.1016/j. jvs.2018.05.229

54. Biancari F, Salenius JP, Heikkinen M, et al. Risk-scoring method for prediction of 30-day postoperative outcome after infrainguinal surgical revascularization for critical lower-limb ischemia: a Finnvasc registry study. World J Surg. 2007;31(1):217-25;discussion 226-7. doi:10.1007/s00268-006-0242-y

55. Schanzer A, Mega J, Meadows J, et al. Risk stratification in critical limb ischemia: derivation and validation of a model to predict amputation-free survival using multicenter surgical outcomes data. J Vasc Surg. 2008;48(6):1464-1471. doi:10.1016/j.jvs.2008.07.062
56. Farber A. Chronic limb-threatening ischemia. $N$ Engl J Med. 2018;379(2):171-180. doi:10.1056/NEJMcp1709326

57. Leskinen Y, Salenius JP, Lehtimäk T, et al. The prevalence of peripheral arterial disease and medial arterial calcification in patients with chronic renal failure: requirements for diagnostics. Am J Kidney Dis. 2002;40(3):472-479. doi:10.1053/ajkd.2002.34885

58. United States Renal Data System. Annual Data Report: Epidemiology of Kidney Disease in the United States. Bethesda, MD: National Institutes of Health, National Institute of Diabetes and Digestive and Kidney Diseases;2018.

59. Owens CD, Ho KJ, Kim S, et al. Refinement of survival prediction in patients undergoing lower extremity bypass surgery: stratification by chronic kidney disease classification. J Vasc Surg. 2007;45 (5):944-952. doi:10.1016/j.jvs.2007.01.025

60. Zlatanovi P, Koncar I, Dragas M, et al. Combined impact of chronic kidney disease and contrast induced acute kidney injury on long-term outcomes in patients with acute lower limb ischaemia. Eur J Vasc Endovasc Surg. 2018;56(1):78-86. doi:10.1016/j.ejvs.2018.03.008

61. Ortmann J, Gahl B, Diehm N, et al. Survival benefits of revascularization in patients with critical limb ischemia and renal insufficiency. J Vasc Surg. 2012;56(3):737-45.e1. doi:10.1016/j.jvs.2012.02.049

62. Kumada Y, Aoyama T, Ishii H, et al. Long-term outcome of percutaneous transluminal angioplasty in chronic haemodialysis patients with peripheral arterial disease. Nephrol Dial Transplant. 2008;23 (12):3996-4001. doi:10.1093/ndt/gfn378

63. Graziani L, Silvestro A, Bertone V, et al. Percutaneous transluminal angioplasty is feasible and effective in patients on chronic dialysis with severe peripheral artery disease. Nephrol Dial Transplant. 2007;22(4):1144-1149. doi:10.1093/ndt/gfl764

64. O'Hare AM, Bertenthal D, Sidawy AN, et al. Renal insufficiency and use of revascularization among a national cohort of men with advanced lower extremity peripheral arterial disease. Clin J Am Soc Nephrol. 2006;1(2):297-304. doi:10.2215/CJN.01070905

65. Lüders F, Bunzemeier H, Engelbertz C, et al. CKD and acute and long-term outcome of patients with peripheral artery disease and critical limb ischemia. Clin J Am Soc Nephrol. 2016;11:216-222.

66. Kumada Y, Nogaki H, Ishii H, et al. Clinical outcome after infrapopliteal bypass surgery in chronic hemodialysis patients with critical limb ischemia. J Vasc Surg. 2015;61(2):400-404. doi:10.1016/j. jvs.2014.09.007

67. Patel VI, Mukhopadhyay S, Guest JM, et al. Impact of severe chronic kidney disease on outcomes of infrainguinal peripheral arterial intervention. J Vasc Surg. 2014;59(2):368-375. doi:10.1016/j. jvs.2013.09.006

68. Andreucci M, Faga T, Serra R, et al. Update on the renal toxicity of iodinated contrast drugs used in clinical medicine. Drug Healthc Patient Saf. 2017;22(4):25-37. doi:10.2147/DHPS.S122207

69. Andreucci M, Faga T, Pisani A, et al. Prevention of contrast-induced nephropathy through a knowledge of its pathogenesis and risk factors. ScientificWorldJournal. 2014;2014:823169. doi:10.1155/ 2014/823169

70. Andreucci M, Faga T, Pisani A, et al. Acute kidney injury by radiographic contrast media: pathogenesis and prevention. Biomed Res Int. 2014;2014:362725.

71. O'Hare AM, Feinglass J, Sidawy AN, et al. Impact of renal insufficiency on short-term morbidity and mortality after lower extremity revascularization: data from the department of veterans affairs' national surgical quality improvement program. J Am Soc Nephrol. 2003;14(5):1287-1295. doi:10.1097/01.ASN.0000061776.60146.02

72. Provenzano M, De Nicola L, Pena MJ, et al. Precision nephrology is a non-negligible state of mind in clinical research: remember the past to face the future. Nephron. 2020;144(10):463-478. doi:10.1159/ 000508983

73. Andreucci M, Provenzano M, Faga T, et al. Aortic aneurysms, chronic kidney disease and metalloproteinases. Biomolecules. 2021;11(2):194. doi:10.3390/biom11020194 
74. Akchurin OM, Kaskel F. Update on inflammation in chronic kidney disease. Blood Purif. 2015;39(1-3):84-92. doi:10.1159/000368940

75. Malhotra R, Katz R, Jotwani V, et al. Urine markers of kidney tubule cell injury and kidney function decline in SPRINT Trial participants with CKD. Clin J Am Soc Nephrol. 2020;15(3):349-358. doi: $10.2215 / \mathrm{CJN} .02780319$

76. Provenzano M, Rivoli L, Garofalo C, et al. Renal resistive index in chronic kidney disease patients: possible determinants and risk profile. PLoS One. 2020;15(4):e230020. doi:10.1371/journal. pone. 0230020

77. Gorriz JL, Molina P, Cervero'n MJ, et al. Vascular calcification in patients with non dialysis CKD over 3 years. Clin J Am Soc Nephrol. 2015;10(4):654-666. doi:10.2215/CJN.07450714

78. Perticone M, Maio R, Sciacqua A, et al. Serum phosphorus levels are associated with endothelial dysfunction in hypertensive patients. Nutr Metab Cardiovasc Dis. 2016;26(8):683-688. doi:10.1016/j. numecd.2016.02.003

79. Provenzano M, Andreucci M, Garofalo C, et al. The association of matrix metalloproteinases with chronic kidney disease and peripheral vascular disease: a light at the end of the tunnel? Biomolecules. 2020;10(1):154. doi:10.3390/biom 10010154

80. Hu Y, Ivashkiv LB. Costimulation of chemokine receptor signaling by matrix metalloproteinase- 9 mediates enhanced migration of IFN-alpha dendritic cells. J Immunol. 2006;176(10):6022-6033. doi:10.4049/jimmunol.176.10.6022

81. Li Q, Park PW, Wilson CL, et al. Matrilysin shedding of syndecan-1 regulates chemokine mobilization and transepithelial efflux of neutrophils in acute lung injury. Cell. 2002;111(5):635-646. doi:10.1016/ S0092-8674(02)01079-6

82. Yamashita CM, Dolgonos L, Zemans RL, et al. Matrix metalloproteinase 3 is a mediator of pulmonary fibrosis. Am J Pathol. 2011;179 (4):1733-1745. doi:10.1016/j.ajpath.2011.06.041

83. Monaco C, Andreakos E, Kiriakidis S, et al. Canonical pathway of nuclear factor kappa B activation selectively regulates proinflammatory and prothrombotic responses in human atherosclerosis. Proc Natl Acad Sci USA. 2004;101(15):5634-5639. doi:10.1073/ pnas. 0401060101

84. Sritharan K, Essex D, Sandison A, et al. Membrane Type-1 matrix metalloproteinase: a key player in carotid plaque instability and symptomatic carotid atherosclerotic disease. Br J Surg. 2008;95:2.

85. De Caridi G, Massara M, Spinelli F, et al. Matrix metalloproteinases and risk stratification in patients undergoing surgical revascularisation for critical limb ischaemia. Int Wound J. 2016;13(4):493-499. doi:10.1111/iwj.12464

86. Gondouin B, Cerini C, Dou L, et al. Indolic uremic solutes increase tissue factor production in endothelial cells by the aryl hydrocarbon receptor pathway. Kidney Int. 2013;84(4):733-744. doi:10.1038/ ki.2013.133
87. Yang $\mathrm{K}, \mathrm{Du} \mathrm{C}$, Wang $\mathrm{X}$, et al. Indoxyl sulfate induces platelet hyperactivity and contributes to chronic kidney disease associated thrombosis in mice. Blood. 2017;129(19):2667-2679. doi:10.1182/ blood-2016-10-744060

88. Provenzano M, Andreucci M, De Nicola L, et al. The role of prognostic and predictive biomarkers for assessing cardiovascular risk in chronic kidney disease patients. Biomed Res Int. 2020;2020:2314128. doi: $10.1155 / 2020 / 2314128$

89. Provenzano M, Rotundo S, Chiodini P, et al. Contribution of predictive and prognostic biomarkers to clinical research on chronic kidney disease. Int $J$ Mol Sci. 2020;21(16):5846. doi:10.3390/ ijms 21165846

90. Liabeuf S, Lenglet A, Desjardins L, et al. Plasma beta-2 microglobulin is associated with cardiovascular disease in uremic patients. Kidney Int. 2012;82(12):1297-1303. doi:10.1038/ki.2012.301

91. Nakano T, Ninomiya T, Sumiyoshi S, et al. Association of kidney function with coronary atherosclerosis and calcification in autopsy samples from Japanese elders: the Hisayama study. Am J Kidney Dis. 2010;55(1):21-30. doi:10.1053/j.ajkd.2009.06.034

92. Heerspink HJL, Gansevoort RT. Albuminuria is an appropriate therapeutic target in patients with CKD: the pro view. Clin J Am Soc Nephrol. 2015;10(6):1079-1088. doi:10.2215/CJN.11511114

93. De Zeeuw D, Heerspink HJL. Time for clinical decision support systems tailoring individual patient therapy to improve renal and cardiovascular outcomes in diabetes and nephropathy. Nephrol Dial Transplant. 2020;35(Supplement_2):ii38-ii42. doi:10.1093/ndt/ gfaa013

94. Heerspink HJL, Parving HH, Andress DL, et al. Atrasentan and renal events in patients with type 2 diabetes and chronic kidney disease (SONAR): a double-blind, randomised, placebo-controlled trial. Lancet. 2019;393(10184):1937-1947.

95. Bakris GL, Agarwal R, Anker SD, et al. Effect of finerenone on chronic kidney disease outcomes in type 2 diabetes. $N$ Engl J Med. 2020;383(23):2219-2229. doi:10.1056/NEJMoa2025845

96. Perkovic V, Jardine MJ, Neal B, et al. Canagliflozin and renal outcomes in type 2 diabetes and Nephropathy. N Engl J Med. 2019;380 (24):2295-2306. doi:10.1056/NEJMoa1811744

97. Wanner C, Inzucchi SE, Lachin JM, et al. Empagliflozin and Progression of Kidney Disease in Type 2 Diabetes. $N$ Engl J Med. 2016;375(4):323-334. doi:10.1056/NEJMoa1515920

98. Provenzano M, Andreucci M, Garofalo C, et al. Selective endothelin A receptor antagonism in patients with proteinuric chronic kidney disease. Expert Opin Investig Drugs. 2021;30(3):253-262. doi:10.1080/13543784.2021.1869720

99. Garimella PS, Hirsch AT. Peripheral artery disease and chronic kidney disease: clinical synergy to improve outcomes. Adv Chronic Kidney Dis. 2014;21(6):460-471.
International Journal of General Medicine

\section{Publish your work in this journal}

The International Journal of General Medicine is an international, peer-reviewed open-access journal that focuses on general and internal medicine, pathogenesis, epidemiology, diagnosis, monitoring and treatment protocols. The journal is characterized by the rapid reporting of reviews, original research and clinical studies
Dovepress

across all disease areas. The manuscript management system is completely online and includes a very quick and fair peer-review system, which is all easy to use. Visit http://www.dovepress.com/ testimonials.php to read real quotes from published authors. 